\title{
The endoplasmic reticulum: structure, function and response to cellular signaling
}

\author{
Dianne S. Schwarz ${ }^{1,2,3} \cdot$ Michael D. Blower ${ }^{1,2}$
}

Received: 8 July 2015/Revised: 21 September 2015/Accepted: 22 September 2015/Published online: 3 October 2015

(C) The Author(s) 2015. This article is published with open access at Springerlink.com

\begin{abstract}
The endoplasmic reticulum (ER) is a large, dynamic structure that serves many roles in the cell including calcium storage, protein synthesis and lipid metabolism. The diverse functions of the ER are performed by distinct domains; consisting of tubules, sheets and the nuclear envelope. Several proteins that contribute to the overall architecture and dynamics of the ER have been identified, but many questions remain as to how the ER changes shape in response to cellular cues, cell type, cell cycle state and during development of the organism. Here we discuss what is known about the dynamics of the ER, what questions remain, and how coordinated responses add to the layers of regulation in this dynamic organelle.
\end{abstract}

Keywords Interphase $\cdot$ Mitosis .

Unfolded protein response - Organization - Fertilization · Phosphorylation

\section{Introduction}

The ER is the largest organelle in the cell and is a major site of protein synthesis and transport, protein folding, lipid and steroid synthesis, carbohydrate metabolism and calcium storage [1-7]. The multi-functional nature of this

Michael D. Blower

blower@molbio.mgh.harvard.edu

1 Department of Molecular Biology, Massachusetts General Hospital, Boston, MA 02114, USA

2 Department of Genetics, Harvard Medical School, Boston, MA 02115, USA

3 Present Address: New England Biolabs, Ipswich, MA 01938, USA organelle requires a myriad of proteins, unique physical structures and coordination with and response to changes in the intracellular environment. Work from a variety of systems has revealed that the ER is composed of multiple different structural domains, each of which is associated with a specific function or functions. However, it is not yet clear how these functional subdomains are organized and how different functional domains translate into different structures.

\section{Protein synthesis and folding}

One of the major functions of the ER is to serve as a site for protein synthesis for secreted and integral membrane proteins [8], as well as a subpopulation of cytosolic proteins [1]. Protein synthesis requires localization of ribosomes to the cytosolic face of the ER, and the canonical pathway that regulates protein synthesis involves co-translational docking of the mRNA:ribosome complex on the ER membrane. Translation of secretory or integral membrane proteins initiates in the cytosol, then ribosomes containing these mRNAs are recruited to the ER membrane via a signal sequence within the amino terminus of the nascent polypeptide that is recognized and bound by the signal recognition particle (SRP) [9, 10]. The complex of mRNA:ribosome:nascent polypeptide:SRP is targeted to the ER where it docks on the SRP receptor [11, 12]. Translation continues on the ER and the emerging polypeptide can co-translationally enter the ER through the translocon [2], which is a channel that contains several Sec proteins and spans the lipid bilayer [13].

Also during this time, or in some cases once translation is complete [3], a signal peptidase cleaves the short signal peptide allowing the free protein to enter the ER lumen 
[14]. If the protein is destined to be an integral membrane protein, determined by the presence of a stretch of hydrophobic residues or stop-transfer membrane anchor sequence, translocation will pause [15]. At this point the protein will be shifted laterally and become anchored within the phospholipid bilayer where it remains [15]. Transmembrane proteins can either contain one hydrophobic stretch of amino acids, and are classified as single pass transmembrane proteins, or contain multiple regions that cross the membrane and are classified as multipass transmembrane proteins [3].

If the protein is not destined to be integrated into the membrane, but instead enter the secretory pathway or the lumen of membrane-bound organelles, the protein begins the process of transport. Once translation is complete and the signal peptide has been cleaved the ribosomes are released back into the cytosol [16, 17]. For mRNAs translated by stably-bound ER ribosomes, mRNAs are released and ribosomes may remain bound to the ER and participate in multiple rounds of translation [18, 19]. For cytosolic proteins translated on ER-bound ribosomes it is not clear how these mRNAs are recruited to the ER or what populations of ribosomes are utilized to initiate translation, although a recent study indicates that the ER-resident protein p180 may play a role in the translation-independent recruitment of mRNAs to the ER [20].

Following protein synthesis and translocation into the ER lumen, a protein destined for secretion must undergo proper folding and modifications, with the aid of chaperones and folding enzymes. These modifications include $\mathrm{N}$-linked glycosylation, disulfide bond formation and oligomerization [3]. At this point the fate of the secretory proteins is determined. If the protein functions in the ER, for example as a chaperone, then proper folding will commence. If the protein is destined for secretion, it will be released by the chaperones and packaged for travel through the Golgi on to a final destination (such as the plasma membrane or secreted) or move into peroxisomes [21]. Additionally, the cytosolic regions of the transmembrane protein may interact with cytosolic proteins or chaperones to properly fold these domains.

On the other hand, even with several proteins and complexes dedicated to folding proteins properly, a fraction of proteins do not achieve native and functional form and are either misfolded or aggregated [22]. These proteins can either remain in the ER or enter the ER-associated degradation (ERAD) pathway mediated by the proteasome, assuring that aberrant polypeptides do not inadvertently enter the secretory pathway [23]. Recognition of misfolded proteins, followed by clearing of these aggregates through the ERAD pathway, needs to be tightly controlled so as not to affect cellular function [23]. Interestingly, there are several connections to activation of ER stress response pathways and pathological human conditions. Several neurodegenerative protein misfolding diseases, such as Alzheimer's disease, activate ER stress response pathways. Additionally, activation of the ER stress response pathway is observed in diabetes, inflammatory bowel disease, and various cancers. How ER stress response pathways play a role in these pathologies is an active area of research and various components of the stress response pathways are being investigated as potential therapeutic targets [24]. In general, the protein synthesis functions of the ER are confined to ER sheets and regulation of ER structure by RNA localization and ER stress will be covered later in this review.

\section{Lipid biogenesis}

While the ER is a major site of protein synthesis, it is also a site of bulk membrane lipid biogenesis [4], which occurs in the endomembrane compartment that includes the ER and Golgi apparatus. Proteins and phospholipids, which are the major lipid component of membranes, are transferred and biochemically modified in the region of the ER that is in close juxtaposition to the Golgi apparatus [25]. This region, known as the ER-Golgi intermediate compartment (ERGIC), is rich in tubules and vesicles [4]. Once lipids are mobilized to the ERGIC they are distributed throughout the cell through organelle contacts or secretory vesicles [26]. The cis-Golgi, which is the closest structure to the ERGIC, leads to the trans-Golgi network where vesicles carrying newly synthesized secretory proteins from the ER form and bud [4]. The trans-Golgi network has traditionally been viewed as the main sorting station in the cell where cytosolic cargo adaptors are recruited to bind, indirectly or directly, and transport proteins or lipids [27].

\section{Calcium $\left(\mathrm{Ca}^{2+}\right)$ metabolism}

Finally, while the ER is a major site of synthesis and transport of a variety of biomolecules, it is also a major store of intracellular $\mathrm{Ca}^{2+}[28,29]$. The typical cytosolic concentration of $\mathrm{Ca}^{2+}$ is $\sim 100 \mathrm{nM}$, while the $\mathrm{Ca}^{2+}$ concentration in the lumen of the ER is $100-800 \mu \mathrm{M}$, and the extracellular $\mathrm{Ca}^{2+}$ concentration is $\sim 2 \mathrm{mM}[6,30]$. The ER contains several calcium channels, ryanodine receptors and inositol 1,4,5-trisphosphate $\left(\mathrm{IP}_{3}\right)$ receptors $\left(\mathrm{IP}_{3} \mathrm{R}\right)$ that are responsible for releasing $\mathrm{Ca}^{2+}$ from the ER into the cytosol when intracellular levels are low [6]. $\mathrm{Ca}^{2+}$ release occurs when phospholipase C (PLC) is stimulated through $\mathrm{G}$ protein-coupled receptor (GPCR) activation [31] and cleaves phosphatidylinositol 4,5 bisphosphate $\left(\mathrm{PIP}_{2}\right)$ into diacyl-glycerol (DAG) and $\mathrm{IP}_{3}$, which can then bind the 
$\mathrm{IP}_{3} \mathrm{R}$ leading to $\mathrm{Ca}^{2+}$ release and transient increase in intracellular $\mathrm{Ca}^{2+}$ levels [6]. Ryanodine receptors (RyRs) act through $\mathrm{Ca}^{2+}$-induced $\mathrm{Ca}^{2+}$ release (CICR), when the receptors bind $\mathrm{Ca}^{2+}$ in response to increased cytoplasmic levels of $\mathrm{Ca}^{2+}$ [32]. In addition, depolarization of t-tubule membranes can lead to conformational changes in voltagedependent $\mathrm{Ca}^{2+}$ channels, such as dyhydropyridine receptors (DHPRs), which interact and activate RyRs leading to $\mathrm{Ca}^{2+}$ release [33]. Furthermore, $\mathrm{Ca}^{2+}$ can leak from the ER into the cytoplasm only to be pumped back into the ER via sarcoendoplasmic reticular $\mathrm{Ca}^{2+}$ ATPases (SERCAs), or can enter the cell from the extracellular media, adding to the layers of regulation [6]. If ER stores of $\mathrm{Ca}^{2+}$ are rapidly depleted through $\mathrm{IP}_{3}$ receptor $\left(\mathrm{IP}_{3} \mathrm{R}\right)$-mediated release a mechanism for $\mathrm{Ca}^{2+}$ entry into the cell is activated, known as store-operated $\mathrm{Ca}^{2+}$ entry (SOCE) [6, 34]. After ER luminal $\mathrm{Ca}^{2+}$ depletion, STIM1 proteins cluster in regions of ER abutting the plasma membrane. At these regions, clustered STIM1 traps plasma membrane-diffusing Orai1 subunits $[35,36]$ and assembles them into active $\mathrm{Ca}^{2+}$ release-activated channels (CRAC) allowing for uptake of extracellular $\mathrm{Ca}^{2+}$ into the ER lumen to restore $\mathrm{Ca}^{2+}$ levels [37-39]. Interestingly, SOCE and activation of CRAC does not depend on, nor sense, changes in levels of $\mathrm{Ca}^{2+}$ in the cytoplasm [6], but senses and responds to changes in luminal $\mathrm{Ca}^{2+}$ concentration.

Calcium is a widespread signaling molecule that can affect diverse processes including localization, function and association of proteins, either with other proteins, organelles or nucleic acids. Release of $\mathrm{Ca}^{2+}$ can result in a wave of $\mathrm{Ca}^{2+}$ that moves through the entire cell [40], a gradient of $\mathrm{Ca}^{2+}$ from the source of release, or a spatiallyrestricted wave from clustered channels known as a $\mathrm{Ca}^{2+}$ spark [41]. One of the most well-studied $\mathrm{Ca}^{2+}$ release events occurs at fertilization following sperm entry [40, 42], but also occurs during muscle contraction and secretion [6] as well as neuronal processes including neurotransmitter release [43]. We will highlight recent evidence that $\mathrm{Ca}^{2+}$ may also play a role in reshaping the ER in response to cellular signals.

\section{Regulation of ER shape and function}

The ER is a complex organelle, involved in protein and lipid synthesis, calcium regulation and interactions with other organelles. The complexity of the ER is reflected in an equally complex physical architecture. The ER is composed of a continuous membrane system that includes the nuclear envelope (NE) and the peripheral ER, defined by flat sheets and branched tubules (Fig. 1). The shape and distribution of these ER domains is regulated by a variety of integral membrane proteins and interactions with other organelles and the cytoskeleton. These interactions are dynamic in nature and reflect changes within the cell, either through cell cycle or developmental state, cell differentiation, intracellular signals or protein interactions. While it is generally known how the basic shapes of ER sheets and tubules are determined, it is relatively unclear how changes in shape or the ratio of sheets to tubules occur in response to specific cellular signals.

Here, we will discuss what is known about how the structures of ER are formed, how the dynamics of the ER are regulated, and how these dynamics change in response to cell cycle state and cellular cues. In addition, we provide examples of how the proteins that are involved in contributing to ER shape are influenced by these cellular cues, such as calcium release, and how this is reflected in the dynamics of the ER and ultimately the function of specialized cells that display varying ratios of sheets to tubules.

\section{ER structure}

There have been several excellent, recent reviews that cover the topic of general ER structure in detail [7, 44-48], so we will limit our review of the basic ER structure to only those factors that may play a role in changing the shape of ER in response to signaling. The ER consists of the nuclear envelope and the peripheral ER, which includes smooth tubules and rough sheets. While the ER is defined as an interconnected network with a continuous membrane, the different structures that make up the ER perform very diverse and specialized functions within the cell.

The nuclear envelope is made up of two lipid bilayers, the inner nuclear membrane (INM) and outer nuclear membrane (ONM), and shares a common lumen with the peripheral ER. Hundreds of nuclear pores spanning the ONM and INM of the nuclear envelope allow transport of molecules, including RNAs and proteins, at various rates of diffusion or regulated transport depending on the size of the molecule. The nuclear envelope is connected to sheets, or cisternae, that make up part of the peripheral ER. Sheets are flat in nature consisting of two lipid bilayers with an intervening lumen, with curved regions located only at the membrane edges. Peripheral ER Sheets may vary in size, but the luminal spacing is very consistent, usually about $50 \mathrm{~nm}$ in mammals and $30 \mathrm{~nm}$ in yeast [49] (Fig. 2). Sheets are usually observed in a stacked conformation and are connected via regions of twisted membranes with helical edges [50]. These rough sheets, as defined by the high density of ribosomes on the cytosolic surface [51, 52], are the main site of synthesis, folding and post-translational modifications for secreted or membrane-bound proteins. In turn, far fewer ribosomes are present on the membrane 

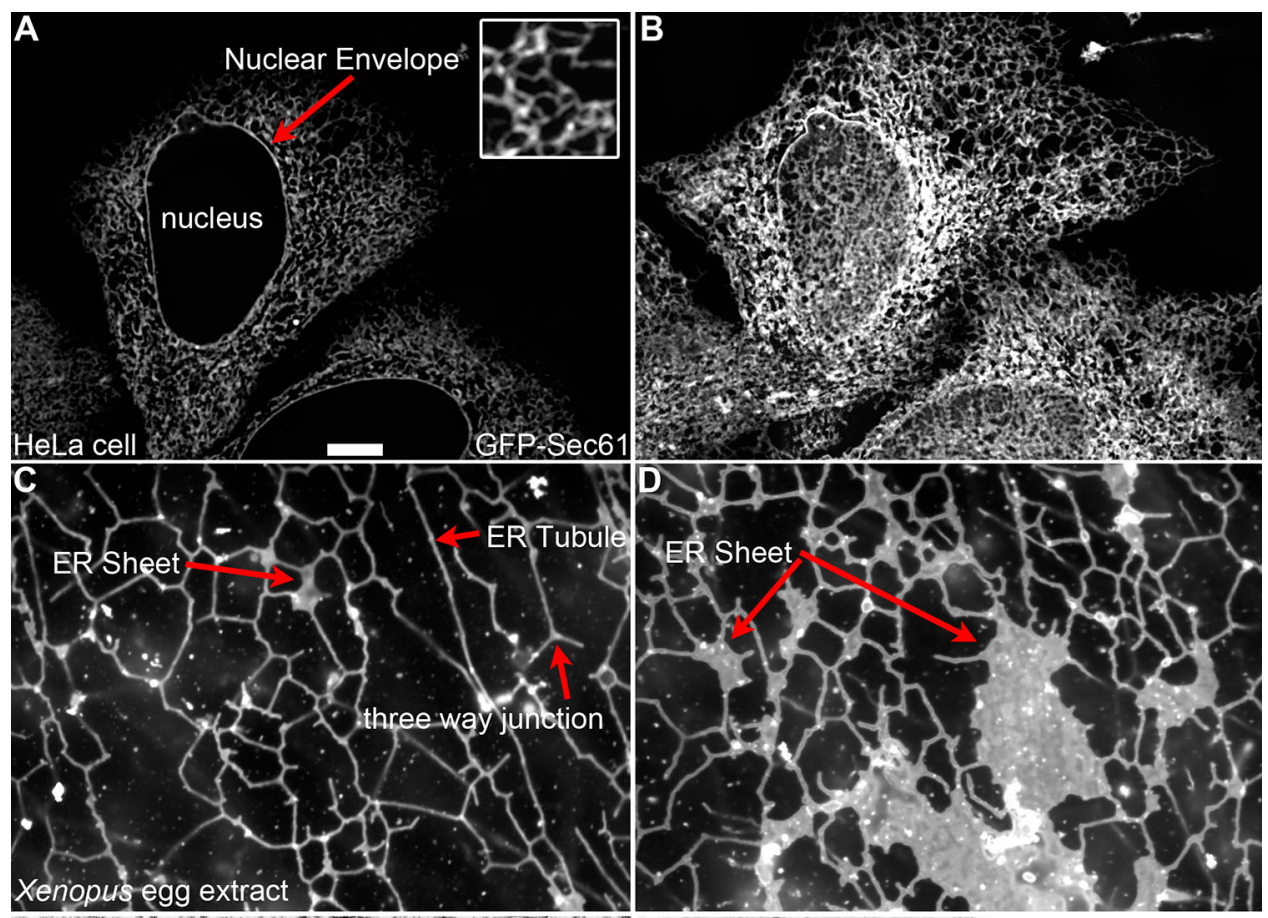

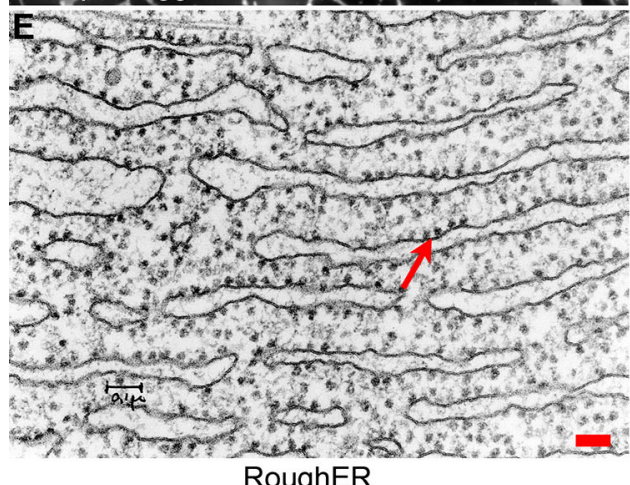

RoughER

Fig. 1 Various ER structural morphologies. a Location of the ER visualized in a HeLa cell transfected with GFP-Sec61 $\beta$. Inset shows the polygonal network of the peripheral ER magnified $\times 3$ relative to the magnification in $\mathbf{a}$. This view highlights the relationship of the ER to the nuclear envelope (red arrow). b ER morphology from the same HeLa cell depicting an image plane closer to the coverslip. This highlights the complexity of the peripheral ER. $\mathbf{c}$ ER network formed in Xenopus egg extracts. Three-way junctions, ER tubules and small

surface of ER tubules [52], which is highly curved and smooth and may not accommodate the binding of large polysomes (Fig. 2). The tubular network is dynamic, continually rearranging and growing, and is defined by threeway junctions that connect individual tubules (Fig. 1). While tubules and sheets possess very different structural features, and hence play a role in different cellular processes, the luminal spacing of both tubules and sheets is similar [49, 52].

Interestingly, ER tubules and sheets are found in all eukaryotic cells [53], though the ratio of sheets to tubules

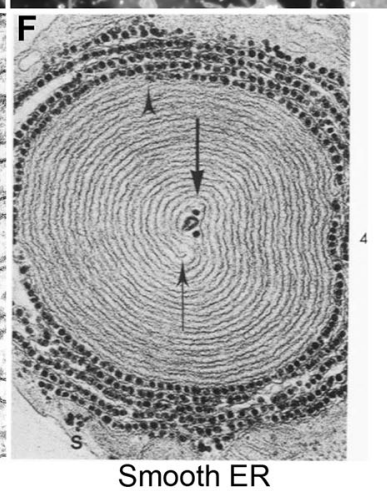

ER sheets are highlighted (red arrows). d ER network formed in Xenopus egg extracts highlighting large ER sheets containing ribosomes (red arrow). Scale bar for $\mathbf{a}-\mathbf{d}$ is $10 \mu \mathrm{M}$ and is shown in a. e Electron micrograph (EM) of rough ER from guinea pig pancreas. Reprinted with permission from James Jamieson. Scale bar is $0.1 \mu \mathrm{M}$. f EM of smooth ER from ocular rabbit muscle. Reprinted with permission from Fig. 4 [164]. Magnification is $\times 50,000$

varies in different cell types and reflects the different functions of these cells. For example, the ER architecture of specialized cells that synthesize vast amounts of secreted proteins, such as pancreatic secretory cells and B cells, is largely made up of sheets (Fig. 1). In turn, cells that are involved in processes including lipid synthesis, calcium signaling and sites of contact for other organelles possess an ER composed of primarily tubules (Fig. 1). Adrenal, liver and muscle cells are all examples of specialized cells with a predominantly tubular network and reflects the function of these cells [54]. 
A

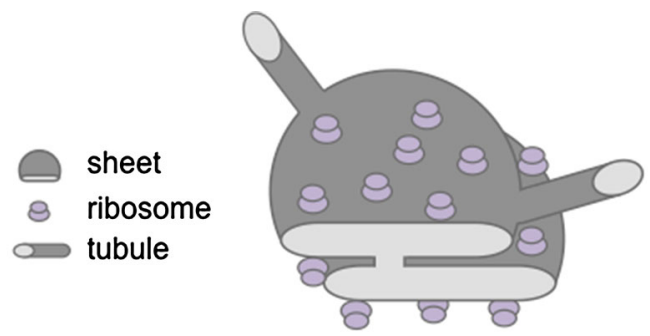

B

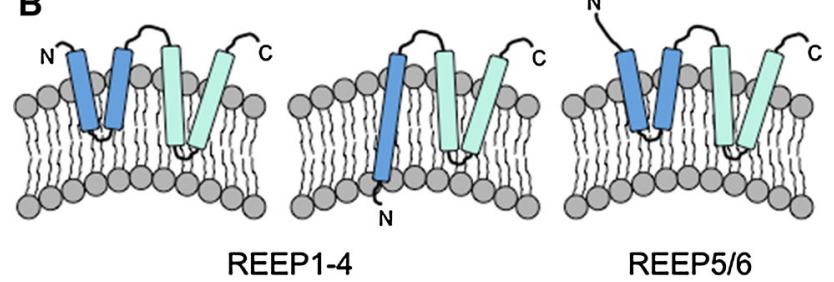

Fig. 2 Structure of ER sheets and tubules. a ER sheets and tubules have a diameter of 30-50 $\mathrm{nm}$ in eukaryotes. Eukaryotic ribosomes are 25-30 $\mathrm{nm}$ and localize to the flat regions of ER sheets, giving the sheets a rough appearance (rough ER). Ribosomes are present in much lower numbers on tubules, giving the tubules a more smooth appearance (smooth ER). b Models of potential hairpin topologies of REEP family proteins that act as wedges to promote bending of the membrane, adapted from [63]

An additional configuration of the peripheral ER includes cortical ER, which abuts the plasma membrane and displays an intermediate phenotype between sheets and tubules with membranes that are both highly curved as well as regions that are flat in nature. Calcium signaling occurs at the contact sites between the plasma membrane and the abutting cortical ER and is necessary for muscle contraction $[55,56]$. Therefore, the morphology and intracellular location of the ER subdomains contribute to the function of these structures and hence the role of the specialized cell in which they are located.

Improved microscopy techniques have allowed for the characterization of different ER structures, and the ratios of these structures to one another, in specialized cell types. When comparing the roles of these cells in the organism, it is clear that the type and amount of peripheral ER present reflects the function of that particular cell type. It is still unclear how these ratios are generated and what cellular signaling pathways play a role in designating which ER type will be most prominent in a particular cell type.

\section{ER shaping proteins}

\section{ER tubules}

Peripheral ER structures are just as distinct and diverse as the set of proteins that contribute to their shape. Several proteins have been identified that promote specific ER structures, but perhaps the most well-studied group of proteins include the reticulon family of proteins that localize to tubules and the highly curved edges of ER sheets $[51,57]$. These integral membrane proteins contribute to the bending of the membrane by forming a transmembrane hairpin topology that acts as a wedge, displacing lipids in the outer leaflet of the bilayer leading to curvature of the membranes [57]. These proteins tend to form oligomers and are much less mobile than other ERresident proteins [58]. Overexpression of some reticulon isoforms leads to formation of long ER tubules at the expense of sheets [58]. In turn, depletion of reticulons, and hence the ability to bend membranes, leads to a reduction in the number of ER tubules, leading to an expansion of peripheral sheets $[57,59,60]$. Therefore, the level of reticulons within a cell determines the abundance and fine structure of ER tubules.

Reticulons do not act alone in shaping ER tubules. Members of the DP1/Yop1/REEP5/6 and REEP1-4 family, which are abundant ER-resident proteins that specifically localize to tubules and edges of sheets, also act as tubulepromoting factors. DP1/Yop1, or REEP5/6 [61], proteins share a similar transmembrane hairpin architecture with the reticulons (Fig. 2), leading to the stabilization of the curved membranes of tubules [57, 58, 62]. Interestingly, REEP1-4 proteins have a topology distinct from REEP5/6 suggesting that these proteins may have slightly different functions in shaping the ER than the closely related REEP5/6 proteins [63] (Fig. 2). Additionally, purified reticulons and DP1/ Yop1 family proteins were able to induce tubule formation from purified vesicles [62], demonstrating that these proteins play an essential role in ER tubule growth.

Reticulons and DP1/Yop1 promote tubule formation, but additional factors are required to promote the formation of the tubular network and characteristic three-way junctions through homotypic fusion. Atlastins, members of the dynamin-like GTPase family, mediate these homotypic fusion events. Depletion by RNAi or expression of dominant-negative atlastin in cells results in a lack of fusion events leading to an abundance of long, unbranched tubules [61]. When a dominant-negative cytoplasmic fragment from Xenopus, which contains the GTPase domain but lacks the transmembrane domain and cytoplasmic tail [64], are introduced into Xenopus interphase extracts ER network formation was blocked [65]. Comparable point mutations that prevent dimerization of the cytoplasmic fragment of human atlastin [66] were made in the Xenopus cytoplasmic atlastin protein, added into interphase extract and had no effect on ER network formation [65]. Furthermore, antibodies directed against atlastin inhibit ER network formation when introduced into Xenopus egg extracts [61]. In Drosophila, atlastin depletion leads to ER fragmentation and purified atlastin is sufficient to catalyze 
GTP-dependent fusion of proteoliposomes [64, 66, 67]. Therefore, studies from multiple organisms, extracts and purified components indicate that atlastin is likely required for catalyzing homotypic vesicle fusion between ER membranes, which is important for proper network formation.

Recently, a few new key players have been identified that are involved in ER dynamics. Work using purified ER vesicles derived from Xenopus eggs has demonstrated that GTP is required for homotypic ER vesicle fusion in the absence of cytosolic factors [57, 68]. Previous studies indicated that GTPases are required for ER fusion events $[69,70]$, and a recent study utilized a proteomics approach to identify Rab10 as a factor required for ER assembly [71]. Knock-down of Rab10, or overexpression of a GDPlocked dominant-negative point mutant, in cultured human cells caused an increase in ER sheets and a decrease in tubules [71]. ER-ER fusion events occurred at regions where Rab10 was enriched. Rab10 was found to co-localize with several lipid-synthesizing enzymes, including phosphoinositol synthase (IS) and choline/ethanolamine phosphotransferase (CEPT1) [71], leading to the possibility that this may represent a previously unidentified ER subdomain or compartment. It is currently not clear what role Rab10 plays in the ER vesicle fusion reaction or how homotypic ER vesicle fusions are coupled to lipid synthesis.

Recent work has also identified a role for Rab18, which is targeted to the ER by Rab3 GTPase activating protein (GAP) complex, in ER dynamics. Depletion of Rab18 leads to a phenotype similar to that observed following Rab10 inhibition [72]. Additionally, when Rab10 is depleted, Rab18 redistributes to peripheral sheets [72]. Therefore, it appears that depletion of either Rab10 or Rab18 prevents the stabilization of ER tubule fusion, reducing the density of tubules resulting in an increase in ER sheets. Depletion of the Caenorhabditis elegans RAB-5, which has been previously implicated in early endosome function [73], phenocopies the peripheral ER defects seen in the RET-1 and YOP-1 (homologs of Rtn4a and DP1) depletions [70]. In addition to the role RAB-5 plays in peripheral ER formation, kinetics of nuclear envelope disassembly is affected in these mutants [70].

In addition to GTPases that may play a direct role in homotypic membrane fusion of vesicles, recent work has demonstrated a role for lipid synthesizing enzymes in controlling the shape and organization of the ER. Inhibition of C-terminal domain (CTD) nuclear envelope phosphatase-1 (CNEP-1), which is enriched on the nuclear envelope and promotes the synthesis of membrane phospholipids, led to the appearance of ectopic sheets that encased the nuclear envelope, interfering with nuclear envelope breakdown [74]. These results reflect the interconnected network of proteins and functions that play a role in shaping the structures of the ER.

The ER is a very dynamic network that is constantly undergoing rearrangements and remodeling [75]. ER tubules are continually fusing and branching resulting in the creation of new three-way junctions. In a competing process, junction sliding and tubule ring closure leads to loss of three-way junctions and the characteristic polygonal structure [76]. Very little is known about the complexes controlling this process, but it was recently discovered that Lunapark (Lnp1) localizes to and stabilizes three-way junctions [77, 78]. Lnp1 binds to reticulons and Yop1, and localization of Lnp1 to junctions is regulated by Sey1p, the yeast homolog of atlastin [78]. Loss of Lnp1 leads to a collapsed and densely reticulated ER network in yeast and human cultured cells [77, 78], though only half of the junctions are bound to Lnp1 [77], which reflects the fluidity of the ER network. If Lnp1 is overexpressed, the protein localizes to the peripheral ER and induces the formation of a large polygonal tubular network [79]. Additionally, formation of this network was inhibited by Lnp1 mutations that blocked $N$-myristoylation [79], an attachment of myristic acid (a 14-carbon saturated fatty acid), indicating that this modification plays a critical role in Lnp1-induced effects on ER morphology. $N$-myristoylation is not required for membrane translocation, topology formation, or protein localization to the ER but may play a role in protein-protein or protein-lipid interactions that are required for morphological changes in the ER, though the exact molecular mechanism of action remains to be elucidated [79].

The actual mechanism for Lnp1-mediated stabilization of three-way junctions is unknown, though recent studies and insights from the structure and domains within the protein shed light on how Lnp1 stabilizes junctions [77, 78]. First, Lnp1 contains two transmembrane domains as well as a zinc finger domain, which is located on the cytoplasmic face of the ER membrane [77]. When cysteines were mutated within the zinc finger domain, the polygons became smaller and regions lacking cortical ER were more apparent as the number of cysteines mutated increased [78]. Therefore, mutations in the zinc finger domain may affect protein-protein interactions, complex formation or interfere with the distribution of resident lipids on the cytoplasmic face of the membrane causing deleterious effects on junction stabilization. In addition, the transmembrane domains may be acting as an inverted wedge, adding to the local negative curvature characteristic of three-way junctions [77], and acting opposite to the positive curvature promoted by reticulons. Another possibility is that multiple Lnp1 proteins may also act 
cooperatively together to stabilize the junction, or Lnp1 may be acting transiently to stabilize or modify lipids or other proteins at junctions [77].

In addition to proteins that regulate membrane structure and dynamics, there is accumulating evidence that changing the nucleic acid content of the ER can also impact ER shape. Early experiments showed that brief treatment of tissue culture cells with the translation inhibitor puromycin, which dissociates mRNA:ribosome complexes, leads to loss of ribosomes from the ER and a loss of ER sheets [51, 80]. This suggests that the presence of mRNA:ribosome complexes may stabilize ER sheets. In support of this hypothesis, our recent work identified an ER-localized ribonuclease, XendoU [81], that changes the RNA content of the ER in response to changes in free $\mathrm{Ca}^{2+}$ concentration $[82,83]$. These changes occur at physiologically relevant levels of $\sim 1.5 \mu \mathrm{M}$, which mimics release of $\mathrm{Ca}^{2+}$ from intra- and extracellular stores at fertilization [42, 84]. A subpopulation of XendoU localizes to the ER and co-immunoprecipitates with a number of ER-resident proteins [82]. Depletion of XendoU leads to the formation of long, unbranched tubules in Xenopus leavis egg extract, and rescue of this phenotype requires intact catalytic activity of the protein, indicating that the nuclease function is critical to proper ER network formation [82]. Furthermore, antibody addition to purified vesicles leads to a block in network formation, demonstrating that XendoU acts on the surface of ER membranes to regulate ER structure [82]. Interestingly, addition of $5^{\prime} 5^{\prime}$-dibromo BAPTA, a strong calcium chelator, blocked vesicle fusion in this system [68]. Depletion of XendoU also leads to a delay in replication and nuclear envelope closure [82], and BAPTA blocks nuclear envelope formation in Xenopus egg extract reconstitution experiments [85]. Together these results suggested that XendoU acts on membranes to degrade RNAs.

Upon vesicle fusion it was found that RNAs were degraded and released from the surface of membranes, suggesting that XendoU acts to degrade these RNAs, as well as release proteins, to clear patches of membrane to allow for vesicle formation leading to network formation [82]. Interestingly, when purified vesicles were treated with increasing concentrations of RNaseA and subjected to the same assay, an increasingly aberrant network formed with large vesicles that were unable to fuse [82]. Results from in vitro studies indicate that $\mathrm{XendoU}$ is activated on membranes in coordination with calcium release to locally degrade RNAs and clear patches of membranes leading to fusion in a controlled manner to fine tune network formation.

Lastly, similar to other proteins that play a role in tubule formation, knock-down of the human homolog EndoU in cultured human cells leads to an expansion of sheets [82]. Additionally, rescue of the expanded sheet phenotype depended on intact catalytic function as observed with recombinant protein in the extract system. Therefore, XendoU is an example of a protein that is activated in response to cellular cues to regulate proper ER formation, and further studies may reveal additional proteins that are regulated in this manner to fine tune organelle structure.

\section{ER sheets}

We have considered how tubules are formed and maintained, which leads the discussion to sheets, the other peripheral ER structure. First, we must consider how sheets are formed. Several mechanisms have been proposed, including the idea that integral membrane proteins can span the intraluminal space and form bridges, connecting the lipid bilayers [51, 86, 87]. These proteins may either stabilize the structure or define the distance between the two lipid layers based on the size of the proteins. Additionally, these proteins or protein complexes may form a scaffold that aids in the stabilization of the sheets or bring the two lipid membranes in closer proximity [86]. Several proteins including Climp63, p180 and kinectin have been implicated in the generation, maintenance and stabilization of ER sheets [51].

In addition to highly enriched membrane proteins and core components of the translocon, Climp63, a coiledcoiled protein with a single transmembrane domain, was identified along with kinectin and p180 in a mass spectrometry screen for abundant integral ER membrane proteins [51]. Through various techniques and in various cell types Climp63 was shown to be a highly abundant protein [88-90] that localizes to perinuclear ER and is absent from the nuclear envelope [91, 92]. Very stable oligomers of Climp63 can form, restricting mobility of the protein along the membrane, promoting localization to the rough ER [92]. Overexpression of Climp63 leads to a massive proliferation of ER sheets while reduction in expression surprisingly does not lead to loss of sheets but instead a decrease in the distance between sheets [51]. Moreover, these sheets are spread diffusely throughout the cytoplasm, reminiscent of the phenotype of cells treated with the translation inhibitor puromycin [51]. This is interesting as the core components of the translocon, the protein channel that interacts with ribosomes and is responsible for translocating nascent peptides into the ER or anchoring transmembrane segments of newly synthesized proteins, were found to be enriched on sheets [93]. Therefore, these results suggest that the role of Climp63 in formation of sheets is likely to involve additional factors and acts as a part of an elaborate regulatory network that balances the production of sheets and tubules. 


\section{ER microtubule interactions}

It is clear that proteins involved in the promotion, maintenance or stabilization of peripheral ER structures function through interactions with additional proteins or structures, and these interactions are key to proper formation of the ER network. Interestingly, several of the proteins discussed above have been shown to interact with microtubules, including Climp63 [91], p180 [94], kinectin [95] and STIM1 (discussed below). One important interaction discussed below is with microtubules. The ER network exhibits several dynamic interactions with microtubules that are important for determining the distribution of the ER within the cell. The two main types of interactions between the ER and microtubules are Tip Attachment Complexes (TACs) and sliding along preformed microtubules by the action of kinesin and dynein motors [96-100]. In cultured cells treated with nocodazole to depolymerize microtubules, the ER retracts from the periphery [101], though the retraction does not occur immediately. Further investigation revealed that sliding events occurred mainly on a small subset of microtubules, modified by acetylation, that are more resistant to nocodazole treatment [76]. Furthermore, ER tubules can form in the absence of microtubules [57, 65, 68], raising many questions and leading several groups to study the interaction between ER and microtubules more in-depth.

In the past 10 years we have learned a great deal about what proteins are responsible for the intrinsic shape of the ER and how these proteins are connected to specific ER subdomains. However, we know very little about how cellular signals communicate with ER shaping proteins to change the shape of the ER in response to cellular signals.

\section{Changes in ER structure during mitosis}

During mitosis many cellular structures are dramatically remodeled to facilitate chromosome segregation. One of the most dramatic examples is changes to the microtubule cytoskeleton that occur as a result of increased microtubule dynamics caused by the action of cyclin-dependent kinases. The increase in microtubule dynamics during mitosis is important for the bipolar attachment of chromosomes to the mitotic spindle and accurate segregation to daughter cells during anaphase [102]. In addition to changes to the microtubule cytoskeleton, essentially all organelles change shape and function during mitosis to facilitate accurate organelle inheritance and orderly chromosome segregation. The ER undergoes dramatic shape changes during mitosis and recent studies are beginning to uncover the mechanisms linked to these structural changes.

In organisms with an open mitosis the nuclear envelope breaks down at the onset of mitosis to allow free exchange between the nucleus and cytoplasm. Nuclear envelope breakdown (NEBD) is a carefully orchestrated process that begins during mitotic prophase [103]. During prophase components of the nuclear pore dissociate from the pore, the nuclear lamina depolymerizes, and the membranebound proteins of the nuclear envelope retract into the general ER. These events free the chromosomes of nuclear lamina and membranes to facilitate chromosome condensation and segregation. In general, the events of nuclear envelope breakdown are thought to be driven by the phosphorylation of components of the NE during mitosis by various mitotic kinases, especially cyclinB:cdk1, although many molecular details are still unclear.

Concomitant with changes that occur to the nuclear envelope during NEBD the ER also begins to undergo dramatic shape changes. Changes in ER shape during mitosis have been studied in many different organisms by both light and electron microscope and these studies have resulted in a conflicting series of reports about the shape of the ER during mitosis. However, during the last few years a consensus has begun to emerge that the mitotic ER is primarily composed of sheets. Early studies using live cell microscopy in both Drosophila and C. elegans embryos demonstrated that the ER changed from a mixture of sheets and tubules to almost exclusively sheets during mitosis $[104,105]$. Additionally, work using thin section transmission EM in HeLa cells also concluded that the majority of the ER was present in sheets throughout mitosis [106]. However, two studies in a variety of mammalian tissue culture cells $[80,107]$ have used both live cell microscopy and electron microscopy to suggest that the ER is primarily tubular during mitosis, and two additional studies [60, 108] also suggested that the ER remained tubular during mitosis and further suggested that end-on binding of ER tubules to chromatin during mitosis initiates nuclear envelope reassembly at the end of mitosis. One potential difficulty in interpreting the shape of the mitotic ER is that most cells round up during mitosis which can make acquisition of light and electron microscopy images difficult and require laborious reconstruction of the images into a three dimensional model. In addition, the mitotic ER is highly dynamic, which can complicate acquisition of live cell images during mitosis. To address these questions a series of recent studies have used both high-resolution, highspeed live cell microscopy and high-resolution EM to demonstrate that the ER is almost exclusively composed of sheets during mitosis $[109,110]$. In addition, these studies demonstrate that the nuclear envelope reforms through the docking of ER sheets onto regions of chromatin that are isolated from spindle microtubules [109]. Finally, to circumvent many or the problems associated with imaging large, three dimensional cells during mitosis a recent study has examined the structure of the ER in vitro using ER 
reconstituted from Xenopus egg extracts [65]. This study convincingly demonstrated that ER formed in mitotic extracts is primarily composed of sheets while interphase ER is primarily composed of tubules. In addition, the authors demonstrated that active cyclinB:cdk1 was sufficient to convert a tubular ER into a primarily sheet based ER. Taken together all of these studies present conflicting views of the shape of the ER during mitosis, but a consensus is emerging from a wide variety of organisms that the mitotic ER is primarily composed of sheets and that the shape changes in the ER are related to changes in cyclin:cdk activity.

In addition to changes in the gross morphology of the ER during mitosis there are also dramatic changes in the distribution of proteins throughout the ER. During interphase the ER is organized into distinct domains with certain proteins defining different domains. For example, the tubule-shaping reticulon protein Rtn4 is exclusively present in the peripheral ER and excluded from the nuclear envelope [57, 60, 110]. In contrast, some proteins, such as the Lamin B receptor and components of the nuclear pore, are exclusively present in the nuclear envelope and are excluded from the peripheral ER [60, 110], while some proteins, like Sec61 $\beta$, are present in all ER subdomains. However, during mitosis the NE retracts into the ER and there is nearly complete mixing of the specialized ERshaping proteins $[60,110]$. At the end of mitosis proteins that define the NE and peripheral ER are rapidly resorted such that they reestablish their characteristic interphase organization $[60,110]$. In addition, it has been shown that overexpression of Rtn4 or knockdown of three reticulons (Rtn1, Rtn3, Rtn4) can either slow or speed the rate of NE reassembly at the end of mitosis, although the mechanism through which these proteins affect NE formation is currently unknown. These studies highlight the massive reorganization that takes place in the ER during mitosis and suggests that different expression levels of specific ER shaping proteins can control ER reorganization during mitosis. However, we know very little about how various ER shaping proteins are resorted to specific domains at the end of mitosis.

Two very recent studies $[111,112]$ have begun to provide insight into the specialized processes that regulate nuclear envelope reformation at the end of mitosis. Both of these studies identified a transient localization of the ESCRT-III complex to the surface of chromatin during late anaphase when the nuclear envelope is beginning to reform. ESCRT-III is best known for its role in the formation of multivesicular bodies during endocytosis, but also has well-documented roles in cytokinesis and viral budding from the plasma membrane [113]. Both studies demonstrated that the membrane binding and deformation properties of ESCRT-III are required for nuclear envelope formation. Additionally, interactions with the microtubule severing enzyme spastin and the ubiquitin recognition factor UFD1 are important for nuclear envelope reformation. These results demonstrate that an endosomal complex is important for regulating NE reformation and suggest that ESCRT-III could potentially play a role in additional aspects of ER dynamics.

The redistribution of ER shaping proteins during mitosis suggests that the fundamental activities of some of these proteins are modified during mitosis. For example, the mitotic ER is composed of primarily sheets, yet Rtn4, which promotes tubule formation [57], is distributed throughout the ER $[60,110]$. This result suggests that the tubule-promoting activity of Rtn4 may be modified during mitosis to facilitate the tubule-to-sheet transition observed during mitosis. Inspection of large-scale phospho-proteomics studies reveals that a large number of ER-shaping proteins have identified mitosis-specific phosphorylation sites [114-121]. Although none of the phosphorylation sites identified in these large-scale screens has been studied in detail their presence and specificity to mitosis suggests that these are likely to be involved in reshaping the ER during mitosis.

In support of the hypothesis that mitosis-specific phosphorylation of ER-shaping proteins regulates ER remodeling during mitosis two studies have examined this phenomenon in detail. A study of the ER sheet promoting protein Climp63 [51] has demonstrated mitosis-specific phosphorylation on three $\mathrm{N}$-terminal residues [121]. Phosphorylation of Climp63 blocks the interaction of Climp63 with microtubules. Additionally, phosphomimetic mutants blocked the interaction of the ER with microtubules during interphase and resulted in an ER composed primarily of sheets, while nonphosphorylatable mutants tethered the ER to microtubules and resulted in an extremely distorted ER. These results suggest that mitotic phosphorylation of Climp63 likely blocks the interaction of the ER with microtubules and could be an important step in the tubule-to-sheet transition that occurs during mitosis. A second study examined the interaction of the ER with growing microtubule plus ends during mitosis. During interphase the ER-associated protein STIM1 interacts with the microtubule plus end-binding protein EB1 to couple ER reshaping to microtubule polymerization [122]. However, during mitosis the ER is excluded from the mitotic spindle and does not exhibit plus tip growth events. A recent study [123] has demonstrated that STIM1 is specifically phosphorylated during mitosis to control the interaction of the ER with microtubules. Specifically, phosphorylation of STIM1 blocks the interaction with the plus-end tracking protein EB1. Nonphosphorylatable mutants of STIM1, created by mutation of $10 \mathrm{~S} / \mathrm{T}$ residues that block all mitotic phosphorylation, result in a recruitment of the ER 
throughout the spindle by restoration of the interaction of STIM1 with EB1, demonstrating that phosphorylation is a major mechanism that regulates the association of the ER with microtubules during mitosis. Interestingly, phosphorylation of STIM1 also blocks activation of SOCE, although this occurs independently of the STIM1:EB1 interaction [118]. Clearly much more work remains before we have a clear understanding of how cell cycle signaling cascades contribute to reshaping of the mitotic ER.

While the above studies demonstrated that phosphorylation of key proteins that link the ER to the microtubule cytoskeleton is important for excluding the ER from the spindle during mitosis a recent study demonstrated the importance of an interaction of the ER with microtubules for clearing the ER from mitotic chromatin. During mitosis the nuclear envelope is absorbed into the ER and is cleared from the surface of the chromatin, however little is known about the mechanisms that regulate ER removal from the chromatin. A recent study used a biochemical approach to identify proteins that bind to both membranes and microtubules to identify new ER proteins REEP3/4 [124]. The authors demonstrate that RNAi against REEP3/4 results in a failure to remove membranes from chromosomes during mitosis, resulting in chromosome segregation defects and internuclear membrane inclusions. Interestingly, the authors further demonstrate that removal of membranes from mitotic chromatin requires the interaction of REEP3/4 with microtubules. However, it is not known if REEP3/4 is subject to phosphoregulation during mitosis or if the microtubulebinding activity or REEP3/4 is required for shaping the ER during interphase. Taken together these three studies demonstrate that interaction of the ER with microtubules is a major mechanism that contributes to shape rearrangement during mitosis and that ER:microtubule interactions are regulated by mitotic phosphorylation. In addition, these studies demonstrate that the ER interacts with microtubules using many different adaptor proteins and that these different adaptor proteins serve different functions during mitosis.

\section{Changes in ER during oocyte maturation and fertilization}

One of the greatest changes during development occurs at fertilization. As in mitosis, the transition from oocyte to embryo requires many coordinated cellular changes including release from meiotic arrest, resumption of mitosis, fusion of pronuclei, activation of signaling cascades and changes in protein expression [125-128]. In order for development to proceed normally, the egg must undergo the proper calcium response in order to initiate the developmental program and embryogenesis [129].

While the exact mechanism and conformational changes vary slightly among all organisms studied, the ER architecture in oocytes of all animals changes including Xenopus [130, 131], sea urchin [132], starfish [133] and mouse [134]. Initial studies in starfish oocytes revealed that the ER is comprised of interconnected sheets of membranes, though following germinal vesicle breakdown (GVBD), the ER sheets wrap around yolk platelets resembling a shell [133]. In immature mouse oocytes, large clusters were found deep within the cytoplasm [134]. Following GVBD, the spindle and surrounding ER migrate to the cortex leading to another round of ER reorganization into vegetally localized clusters in the metaphase II egg in addition to a finer reticular network throughout the egg [134, 135]. Interestingly, these steps are dependent on the microtubule network as nocodazole and inhibition of cytoplasmic dynein both prevent the ER reorganization [135]. Formation of the ER clusters is prevented by the depolymerization of microfilaments, but not microtubules [135]. Given the timing of each of these reorganizations, it seems likely that they are related to increases in cyclinB:cdk1 activity that occurs upon oocyte maturation [136]. These observations show an additional time in development where the ER and microtubule network interact to regulate ER structure.

In Xenopus immature oocytes, the network in both the animal (pigmented) half and vegetal (unpigemented) half appears to be uniform and consists of tubules and individual, unstacked sheets [130]. Additionally, the vegetal half contains annulate lamellae, stacks of sheets with membranes containing densely packed nuclear pores [130]. In mature eggs, the ER in the animal half is unchanged, however the annulate lamellae in the vegetal half disappeared. Interestingly, it has been proposed that the annulate lamellae share many properties with the nuclear envelope [137]. In place of the annulate lamellae dense, irregularly shaped ER clusters were present. The appearance of these clusters coincided with germinal vesicle breakdown. These clusters disappeared and reappeared throughout maturation and upon fertilization dispersed and permanently disappeared. The reorganization of the ER is coupled to the cell cycle as the clusters present in mature eggs contain $\mathrm{IP}_{3}$ receptors [130] and release calcium from $\mathrm{IP}_{3}$ channels at fertilization [138, 139].

Along with these changes comes a transient intracellular calcium wave, initiated during sperm entry, released from the ER and extracellular stores [40, 42, 140-142]. There is one major difference in eggs of mice versus eggs of frogs. Frogs, as well as sea urchin [143] and starfish [133, 144] have a single calcium transient at fertilization [145]. Other animals, including mice and humans, have multiple smaller calcium transients following fertilization, and these differences may be reflected in the ER organization in mature eggs [145]. Mice [134] and frogs display ER clusters that are similar in size and location (the side opposite the 
meiotic spindle) and possess $\mathrm{IP}_{3}$ receptors [130, 146]. However, fertilization in mice occurs on the side with the ER clusters whereas fertilization in frogs occurs in the animal pole where the meiotic spindle is located. Therefore, the clusters may be involved in secondary calcium wave propagation. The organization of the ER network, and the reorganization throughout oogenesis, serves as a functional consequence of calcium signaling and propagation in these organisms [129]. We currently do not know much about the molecular mechanisms that lead to changes in ER shape during meiotic maturation and fertilization, and this should be a major are of research interest.

\section{ER changes in response to ER stress}

As seen so far, the ER is an organelle of many different functions that must be tightly regulated to carry out the proper functions. One of the most prominent functions of the ER is protein synthesis. Even with several chaperones and folding enzymes in place, an accumulation of unfolded or misfolded proteins in the lumen of the ER can occur. When the cell undergoes this type of stress there are several things that must occur to retain balance and proper function, including translational inhibition, degradation of unfolded or misfolded proteins, and an increase in the production of chaperones and folding enzymes to restore normal function of the ER and the cell. If the balance is not restored it can lead to cell death or apoptosis [147], therefore achieving normal function is critical to the survival of the cell.

As discussed above, once a peptide destined for secretion has entered the lumen of the cell, there are several modifications that occur, including N-linked glycosylation, disulfide bond formation and oligomerization [3]. N-linked glycosylation can occur co-translationally as the protein is translocated into the ER lumen. The oligosaccharyltransferase (OST) can modify the Asparagine within the Asn-XSer/Thr sequence once it has traversed approximately 13 amino acids into the ER lumen [148], which improves the kinetics and thermodynamics of folding for proteins [149, 150]. Misfolding can occur due to the unique environment of the lumen and the high protein concentration of both newly synthesized proteins, proteins ready for secretion and proteins that act as molecular chaperones and folding enzymes. Logistically, due to the high protein concentration and packing in the lumen, the folding enzymes must first identify and find the proper target protein for folding to take place. If proteins are not modified correctly, the lack of glucose residues is recognized by the ER and proteins including UDP-glucose:glycoprotein glucosyltransferase (UGGT) in an attempt to re-glycosylate the protein [151153]. If the normal folding process is not restored, hydrophobic residues are exposed and bound by Grp78, accumulation of these proteins occurs and the unfolded protein response (UPR) is activated [154, 155]. The first action of the UPR is to increase ER abundance to accommodate the needs of the cell to properly fold the proteins, leading to an expansion of the ER through the generation of sheets [156] and an increase in the ER folding machinery.

The UPR consists of three parallel branches that are activated upon stress and include inositol requiring enzyme 1 (IRE1) by nonconventional splicing, double-stranded RNA-activated protein kinase (PKR)-like ER kinase (PERK) through translational control by phosphorylating eIF2 $\alpha$, and activating transcription factor 6 (ATF6) through regulated proteolysis [155]. Briefly, activation of these pathways lead to production of b-ZIP transcription factors that activate UPR genes [155]. First, ER-resident IRE1, a transmembrane endoribonuclease, mediates the post-transcriptional, non-canonical splicing of XBP1 mRNA that is localized to the ER [157-159] and encodes a transcription factor involved in upregulating additional stress response genes. Additionally, the nuclease activity of IRE1 is involved in degradation of a subset of ER-associated RNAs in a process known as IRE1-dependent decay (RIDD) [160, 161]. The cell has evolved this mechanism to reduce the translational load on the ER by removing mRNAs that otherwise would be translated, and may be one way for the cell to upregulate stress-response genes that are needed in the UPR. Although it is clear that ER-stress leads to large scale changes in the protein and RNA content of the ER, it is not yet clear if this leads to immediate structural reorganization in order to accommodate the new needs of the organelle. In addition, it is not yet clear if activation of stress-responsive signaling pathways leads to the modification of intrinsic structural components of the ER. Interestingly, it has been observed that splicing of XBP1 is activated during meiosis in both Xenopus and budding yeast $[162,163]$, suggesting that changes in ER structure during meiosis could be linked to the ER stress response. These would both be interesting avenues of future research exploring structural changes in the ER in response to cellular signaling cues.

\section{Closing remarks}

The ER is a complex organelle that plays a pivotal role in protein and lipid synthesis, calcium storage and stress response. Changes in structure in response to cell cycle or developmental state render this organelle highly dynamic. Several proteins play a role in the proper formation of the different structures of the peripheral ER including the nuclear envelope, sheets and tubules. Regulation exists at multiple steps in the formation and maintenance of these structures, and the ratios of these structures are very 
different in cells of different functions. In general, cells involved in synthesizing large amounts of protein have higher ratios of sheets, whereas cells involved in lipid synthesis or signaling with other organelles would have higher ratios of tubules. The generation of these structures relies on a myriad of proteins, involved in either structural aspects of ER morphology by directly affecting the phospholipid bilayer and curvature of membranes or mediating interactions with other organelles or the cytoskeleton. In addition, proteins with other functions, including nucleases and GTPases, also play a role in network formation. Recent work has begun to connect our knowledge of the proteins that provide the fundamental shape of the ER to signaling pathways, but much work remains to be done to understand how developmental, cell cycle, and stress pathways change the fundamental shape of the ER in different circumstances. Recent work on several different human diseases has highlighted a role for several different ER-shaping proteins in diverse diseases such as Alzheimer's and Hereditary Spastic Paraplegia (HSP) [reviewed in 7]. The strong link of ER-shaping proteins to hereditary human diseases highlights the need for further research into the basic biology of the ER and how this biology changes in response to changes in cellular environment.

Open Access This article is distributed under the terms of the Creative Commons Attribution 4.0 International License (http:// creativecommons.org/licenses/by/4.0/), which permits unrestricted use, distribution, and reproduction in any medium, provided you give appropriate credit to the original author(s) and the source, provide a link to the Creative Commons license, and indicate if changes were made.

\section{References}

1. Reid DW, Nicchitta CV (2015) Diversity and selectivity in mRNA translation on the endoplasmic reticulum. Nat Rev Mol Cell Biol 16(4):221-231. doi:10.1038/nrm3958

2. Rapoport TA (2007) Protein translocation across the eukaryotic endoplasmic reticulum and bacterial plasma membranes. Nature 450(7170):663-669. doi:10.1038/nature06384

3. Braakman I, Hebert DN (2013) Protein folding in the endoplasmic reticulum. Cold Spring Harb Perspect Biol 5(5):a013201. doi:10.1101/cshperspect.a013201

4. Fagone P, Jackowski S (2009) Membrane phospholipid synthesis and endoplasmic reticulum function. J Lipid Res 50(Suppl):S311-S316. doi:10.1194/jlr.R800049-JLR200

5. Hebert DN, Garman SC, Molinari M (2005) The glycan code of the endoplasmic reticulum: asparagine-linked carbohydrates as protein maturation and quality-control tags. Trends Cell Biol 15(7):364-370. doi:10.1016/j.tcb.2005.05.007

6. Clapham DE (2007) Calcium signaling. Cell 131(6):1047-1058. doi:10.1016/j.cell.2007.11.028

7. Westrate LM, Lee JE, Prinz WA, Voeltz GK (2015) Form follows function: the importance of endoplasmic reticulum shape. Annu Rev Biochem 84:791-811. doi:10.1146/annurev-biochem072711-163501
8. Jan CH, Williams CC, Weissman JS (2014) Principles of ER cotranslational translocation revealed by proximity-specific ribosome profiling. Science 346(6210):1257521. doi:10.1126/ science. 1257521

9. Walter P, Blobel G (1981) Translocation of proteins across the endoplasmic reticulum. II. Signal recognition protein (SRP) mediates the selective binding to microsomal membranes of invitro-assembled polysomes synthesizing secretory protein. J Cell Biol 91(2 Pt 1):551-556

10. Walter P, Ibrahimi I, Blobel G (1981) Translocation of proteins across the endoplasmic reticulum. I. Signal recognition protein (SRP) binds to in-vitro-assembled polysomes synthesizing secretory protein. J Cell Biol 91(2 Pt 1):545-550

11. Gilmore R, Blobel G, Walter P (1982) Protein translocation across the endoplasmic reticulum. I. Detection in the microsomal membrane of a receptor for the signal recognition particle. J Cell Biol 95(2 Pt 1):463-469

12. Meyer DI, Krause E, Dobberstein B (1982) Secretory protein translocation across membranes-the role of the "docking protein'. Nature 297(5868):647-650

13. Deshaies RJ, Sanders SL, Feldheim DA, Schekman R (1991) Assembly of yeast Sec proteins involved in translocation into the endoplasmic reticulum into a membrane-bound multisubunit complex. Nature 349(6312):806-808. doi:10.1038/349806a0

14. Evans EA, Gilmore R, Blobel G (1986) Purification of microsomal signal peptidase as a complex. Proc Natl Acad Sci USA 83(3):581-585

15. Blobel G (1980) Intracellular protein topogenesis. Proc Natl Acad Sci U S A 77(3):1496-1500

16. Seiser RM, Nicchitta CV (2000) The fate of membrane-bound ribosomes following the termination of protein synthesis. J Biol Chem 275(43):33820-33827. doi:10.1074/jbc.M004462200

17. Potter MD, Nicchitta CV (2000) Regulation of ribosome detachment from the mammalian endoplasmic reticulum membrane. J Biol Chem 275(43):33828-33835. doi:10.1074/jbc. M005294200

18. Potter MD, Nicchitta CV (2002) Endoplasmic reticulum-bound ribosomes reside in stable association with the translocon following termination of protein synthesis. J Biol Chem 277(26):23314-23320. doi:10.1074/jbc.M202559200

19. Jagannathan S, Reid DW, Cox AH, Nicchitta CV (2014) De novo translation initiation on membrane-bound ribosomes as a mechanism for localization of cytosolic protein mRNAs to the endoplasmic reticulum. RNA 20(10):1489-1498. doi:10.1261/ rna.045526.114

20. Cui XA, Zhang H, Palazzo AF (2012) p180 promotes the ribosome-independent localization of a subset of mRNA to the endoplasmic reticulum. PLoS Biol 10(5):e1001336. doi:10. 1371/journal.pbio. 1001336

21. van der Zand A, Gent J, Braakman I, Tabak HF (2012) Biochemically distinct vesicles from the endoplasmic reticulum fuse to form peroxisomes. Cell 149(2):397-409. doi:10.1016/j. cell.2012.01.054

22. Hartl FU, Hayer-Hartl M (2009) Converging concepts of protein folding in vitro and in vivo. Nat Struct Mol Biol 16(6):574-581. doi:10.1038/nsmb.1591

23. Ruggiano A, Foresti O, Carvalho P (2014) Quality control: eRassociated degradation: protein quality control and beyond. J Cell Biol 204(6):869-879. doi:10.1083/jcb.201312042

24. Ryno LM, Wiseman RL, Kelly JW (2013) Targeting unfolded protein response signaling pathways to ameliorate protein misfolding diseases. Curr Opin Chem Biol 17(3):346-352. doi:10. 1016/j.cbpa.2013.04.009

25. Glick BS, Nakano A (2009) Membrane traffic within the Golgi apparatus. Annu Rev Cell Dev Biol 25:113-132. doi:10.1146/ annurev.cellbio.24.110707.175421 
26. Appenzeller-Herzog C, Hauri HP (2006) The ER-Golgi intermediate compartment (ERGIC): in search of its identity and function. J Cell Sci 119(Pt 11):2173-2183. doi:10.1242/jcs.03019

27. Guo Y, Sirkis DW, Schekman R (2014) Protein Sorting at the trans-Golgi network. Annu Rev Cell Dev Biol 30:169-206. doi:10.1146/annurev-cellbio-100913-013012

28. Jaffe LF (1983) Sources of calcium in egg activation: a review and hypothesis. Dev Biol 99(2):265-276 0012-1606(83)90276-2 [pii]

29. Eisen A, Reynolds GT (1985) Source and sinks for the calcium released during fertilization of single sea urchin eggs. J Cell Biol 100(5):1522-1527

30. Samtleben S, Jaepel J, Fecher C, Andreska T, Rehberg M, Blum R (2013) Direct imaging of ER calcium with targeted-esterase induced dye loading (TED). J Vis Exp 75:e50317. doi:10.3791/ 50317

31. Oude Weernink PA, Han L, Jakobs KH, Schmidt M (2007) Dynamic phospholipid signaling by $\mathrm{G}$ protein-coupled receptors. Biochim Biophys Acta 1768(4):888-900. doi:10.1016/j. bbamem.2006.09.012

32. Endo M (2009) Calcium-induced calcium release in skeletal muscle. Physiol Rev 89(4):1153-1176. doi:10.1152/physrev. 00040.2008

33. Fill M, Copello JA (2002) Ryanodine receptor calcium release channels. Physiol Rev 82(4):893-922. doi:10.1152/physrev. 00013.2002

34. Putney JW Jr (2005) Capacitative calcium entry: sensing the calcium stores. J Cell Biol 169(3):381-382. doi:10.1083/jcb. 200503161

35. Feske S, Gwack Y, Prakriya M, Srikanth S, Puppel SH, Tanasa B, Hogan PG, Lewis RS, Daly M, Rao A (2006) A mutation in Orail causes immune deficiency by abrogating CRAC channel function. Nature 441(7090):179-185. doi:10.1038/nature04702

36. Zhang SL, Yeromin AV, Zhang XH, Yu Y, Safrina O, Penna A, Roos J, Stauderman KA, Cahalan MD (2006) Genome-wide RNAi screen of $\mathrm{Ca}(2+)$ influx identifies genes that regulate $\mathrm{Ca}(2+)$ release-activated $\mathrm{Ca}(2+)$ channel activity. Proc Natl Acad Sci USA 103(24):9357-9362. doi:10.1073/pnas. 0603161103

37. Parekh AB, Penner R (1997) Store depletion and calcium influx. Physiol Rev 77(4):901-930

38. Roos J, DiGregorio PJ, Yeromin AV, Ohlsen K, Lioudyno M, Zhang S, Safrina O, Kozak JA, Wagner SL, Cahalan MD, Velicelebi G, Stauderman KA (2005) STIM1, an essential and conserved component of store-operated $\mathrm{Ca}^{2+}$ channel function. J Cell Biol 169(3):435-445. doi:10.1083/jcb.200502019

39. Zhang SL, Yu Y, Roos J, Kozak JA, Deerinck TJ, Ellisman MH, Stauderman KA, Cahalan MD (2005) STIM1 is a $\mathrm{Ca}^{2+}$ sensor that activates CRAC channels and migrates from the $\mathrm{Ca} 2+$ store to the plasma membrane. Nature 437(7060):902-905. doi:10. 1038/nature04147

40. Gilkey JC, Jaffe LF, Ridgway EB, Reynolds GT (1978) A free calcium wave traverses the activating egg of the medaka, Oryzias latipes. J Cell Biol 76(2):448-466

41. Cheng H, Lederer WJ, Cannell MB (1993) Calcium sparks: elementary events underlying excitation-contraction coupling in heart muscle. Science 262(5134):740-744

42. Busa WB, Nuccitelli R (1985) An elevated free cytosolic $\mathrm{Ca}^{2+}$ wave follows fertilization in eggs of the frog, Xenopus laevis. J Cell Biol 100(4):1325-1329

43. Mulkey RM, Zucker RS (1991) Action potentials must admit calcium to evoke transmitter release. Nature 350(6314):153-155. doi:10.1038/350153a0

44. English AR, Voeltz GK (2013) Endoplasmic reticulum structure and interconnections with other organelles. Cold Spring Harb Perspect Biol 5(4):a013227. doi:10.1101/cshperspect.a013227
45. Friedman JR, Voeltz GK (2011) The ER in 3D: a multifunctional dynamic membrane network. Trends Cell Biol 21(12):709-717. doi:10.1016/j.tcb.2011.07.004

46. English AR, Zurek N, Voeltz GK (2009) Peripheral ER structure and function. Curr Opin Cell Biol 21(4):596-602. doi:10.1016/j. ceb.2009.04.004

47. Shibata Y, Voeltz GK, Rapoport TA (2006) Rough sheets and smooth tubules. Cell 126(3):435-439. doi:10.1016/j.cell.2006. 07.019

48. Hu J, Prinz WA, Rapoport TA (2011) Weaving the web of ER tubules. Cell 147(6):1226-1231. doi:10.1016/j.cell.2011.11.022

49. Bernales S, McDonald KL, Walter P (2006) Autophagy counterbalances endoplasmic reticulum expansion during the unfolded protein response. PLoS Biol 4(12):e423. doi:10.1371/ journal.pbio. 0040423

50. Terasaki M, Shemesh T, Kasthuri N, Klemm RW, Schalek R, Hayworth KJ, Hand AR, Yankova M, Huber G, Lichtman JW, Rapoport TA, Kozlov MM (2013) Stacked endoplasmic reticulum sheets are connected by helicoidal membrane motifs. Cell 154(2):285-296. doi:10.1016/j.cell.2013.06.031

51. Shibata Y, Shemesh T, Prinz WA, Palazzo AF, Kozlov MM, Rapoport TA (2010) Mechanisms determining the morphology of the peripheral ER. Cell 143(5):774-788. doi:10.1016/j.cell. 2010.11.007

52. West M, Zurek N, Hoenger A, Voeltz GK (2011) A 3D analysis of yeast ER structure reveals how ER domains are organized by membrane curvature. J Cell Biol 193(2):333-346. doi:10.1083/ jcb.201011039

53. Staehelin LA (1997) The plant ER: a dynamic organelle composed of a large number of discrete functional domains. Plant $\mathrm{J}$ 11(6):1151-1165

54. Baumann O, Walz B (2001) Endoplasmic reticulum of animal cells and its organization into structural and functional domains. Int Rev Cytol 205:149-214

55. Block BA, Imagawa T, Campbell KP, Franzini-Armstrong C (1988) Structural evidence for direct interaction between the molecular components of the transverse tubule/sarcoplasmic reticulum junction in skeletal muscle. J Cell Biol 107(6 Pt 2):2587-2600

56. Takeshima H, Komazaki S, Nishi M, Iino M, Kangawa K (2000) Junctophilins: a novel family of junctional membrane complex proteins. Mol Cell 6(1):11-22 (S1097-2765(05)00005-5 [pii])

57. Voeltz GK, Prinz WA, Shibata Y, Rist JM, Rapoport TA (2006) A class of membrane proteins shaping the tubular endoplasmic reticulum. Cell 124(3):573-586. doi:10.1016/j.cell.2005.11.047

58. Shibata Y, Voss C, Rist JM, Hu J, Rapoport TA, Prinz WA, Voeltz GK (2008) The reticulon and DP1/Yop1p proteins form immobile oligomers in the tubular endoplasmic reticulum. J Biol Chem 283(27):18892-18904. doi:10.1074/jbc.M800986200

59. De Craene JO, Coleman J, Estrada de Martin P, Pypaert M, Anderson S, Yates JR 3rd, Ferro-Novick S, Novick P (2006) Rtn1p is involved in structuring the cortical endoplasmic reticulum. Mol Biol Cell 17(7):3009-3020. doi:10.1091/mbc.E0601-0080

60. Anderson DJ, Hetzer MW (2008) Reshaping of the endoplasmic reticulum limits the rate for nuclear envelope formation. J Cell Biol 182(5):911-924. doi:10.1083/jcb.200805140

61. Hu J, Shibata Y, Zhu PP, Voss C, Rismanchi N, Prinz WA, Rapoport TA, Blackstone C (2009) A class of dynamin-like GTPases involved in the generation of the tubular ER network. Cell 138(3):549-561. doi:10.1016/j.cell.2009.05.025

62. Hu J, Shibata Y, Voss C, Shemesh T, Li Z, Coughlin M, Kozlov MM, Rapoport TA, Prinz WA (2008) Membrane proteins of the endoplasmic reticulum induce high-curvature tubules. Science 319(5867):1247-1250. doi:10.1126/science.1153634 
63. Park SH, Zhu PP, Parker RL, Blackstone C (2010) Hereditary spastic paraplegia proteins REEP1, spastin, and atlastin-1 coordinate microtubule interactions with the tubular ER network. J Clin Invest 120(4):1097-1110. doi:10.1172/JCI40979

64. Bian X, Klemm RW, Liu TY, Zhang M, Sun S, Sui X, Liu X, Rapoport TA, Hu J (2011) Structures of the atlastin GTPase provide insight into homotypic fusion of endoplasmic reticulum membranes. Proc Natl Acad Sci USA 108(10):3976-3981. doi:10.1073/pnas.1101643108

65. Wang S, Romano FB, Field CM, Mitchison TJ, Rapoport TA (2013) Multiple mechanisms determine ER network morphology during the cell cycle in Xenopus egg extracts. J Cell Biol 203(5):801-814. doi:10.1083/jcb.201308001

66. Byrnes LJ, Sondermann H (2011) Structural basis for the nucleotide-dependent dimerization of the large $\mathrm{G}$ protein atlastin-1/SPG3A. Proc Natl Acad Sci USA 108(6):2216-2221. doi:10.1073/pnas.1012792108

67. Orso G, Pendin D, Liu S, Tosetto J, Moss TJ, Faust JE, Micaroni M, Egorova A, Martinuzzi A, McNew JA, Daga A (2009) Homotypic fusion of ER membranes requires the dynamin-like GTPase atlastin. Nature 460(7258):978-983. doi:10.1038/ nature 08280

68. Dreier L, Rapoport TA (2000) In vitro formation of the endoplasmic reticulum occurs independently of microtubules by a controlled fusion reaction. J Cell Biol 148(5):883-898

69. Turner MD, Plutner H, Balch WE (1997) A Rab GTPase is required for homotypic assembly of the endoplasmic reticulum. J Biol Chem 272(21):13479-13483

70. Audhya A, Desai A, Oegema K (2007) A role for Rab5 in structuring the endoplasmic reticulum. J Cell Biol 178(1):43-56. doi:10.1083/jcb.200701139

71. English AR, Voeltz GK (2013) Rab10 GTPase regulates ER dynamics and morphology. Nat Cell Biol 15(2):169-178. doi:10. $1038 / \mathrm{ncb} 2647$

72. Gerondopoulos A, Bastos RN, Yoshimura S, Anderson R, Carpanini S, Aligianis I, Handley MT, Barr FA (2014) Rab18 and a Rab18 GEF complex are required for normal ER structure. J Cell Biol 205(5):707-720. doi:10.1083/jcb.201403026

73. Stenmark H (2009) Rab GTPases as coordinators of vesicle traffic. Nat Rev Mol Cell Biol 10(8):513-525. doi:10.1038/ nrm2728

74. Bahmanyar S, Biggs R, Schuh AL, Desai A, Muller-Reichert T, Audhya A, Dixon JE, Oegema K (2014) Spatial control of phospholipid flux restricts endoplasmic reticulum sheet formation to allow nuclear envelope breakdown. Genes Dev 28(2):121-126. doi:10.1101/gad.230599.113

75. Lee C, Chen LB (1998) Dynamic behavior of endoplasmic reticulum in living cells. Cell 54(1):37-46 (0092-8674(88)901778 [pii])

76. Friedman JR, Webster BM, Mastronarde DN, Verhey KJ, Voeltz GK (2010) ER sliding dynamics and ER-mitochondrial contacts occur on acetylated microtubules. J Cell Biol 190(3):363-375. doi:10.1083/jcb.200911024

77. Chen S, Desai T, McNew JA, Gerard P, Novick PJ, FerroNovick S (2015) Lunapark stabilizes nascent three-way junctions in the endoplasmic reticulum. Proc Natl Acad Sci USA 112(2):418-423. doi:10.1073/pnas.1423026112

78. Chen S, Novick P, Ferro-Novick S (2012) ER network formation requires a balance of the dynamin-like GTPase Seylp and the Lunapark family member Lnplp. Nat Cell Biol 14(7):707-716. doi:10.1038/ncb2523

79. Moriya K, Nagatoshi K, Noriyasu Y, Okamura T, Takamitsu E, Suzuki T, Utsumi T (2013) Protein $N$-myristoylation plays a critical role in the endoplasmic reticulum morphological change induced by overexpression of protein Lunapark, an integral membrane protein of the endoplasmic reticulum. PLoS One 8(11):e78235. doi:10.1371/journal.pone.0078235

80. Puhka M, Vihinen H, Joensuu M, Jokitalo E (2007) Endoplasmic reticulum remains continuous and undergoes sheet-to-tubule transformation during cell division in mammalian cells. J Cell Biol 179(5):895-909. doi:10.1083/jcb.200705112

81. Laneve P, Altieri F, Fiori ME, Scaloni A, Bozzoni I, Caffarelli E (2003) Purification, cloning, and characterization of XendoU, a novel endoribonuclease involved in processing of intron-encoded small nucleolar RNAs in Xenopus laevis. J Biol Chem 278(15):13026-13032 M211937200 [pii]

82. Schwarz DS, Blower MD (2014) The calcium-dependent ribonuclease XendoU promotes ER network formation through local RNA degradation. J Cell Biol 207(1):41-57. doi:10.1083/ jcb.201406037

83. Seidel CW, Peck LJ (1994) Purification of a calcium dependent ribonuclease from Xenopus laevis. Nucleic Acids Res 22(8):1456-1462

84. Lorca T, Galas S, Fesquet D, Devault A, Cavadore JC, Doree M (1991) Degradation of the proto-oncogene product p39mos is not necessary for cyclin proteolysis and exit from meiotic metaphase: requirement for a $\mathrm{Ca}(2+)$-calmodulin dependent event. EMBO J 10(8):2087-2093

85. Sullivan KM, Busa WB, Wilson KL (1993) Calcium mobilization is required for nuclear vesicle fusion in vitro: implications for membrane traffic and IP3 receptor function. Cell 73(7):1411-1422 0092-8674(93)90366-X [pii]

86. Shibata Y, Hu J, Kozlov MM, Rapoport TA (2009) Mechanisms shaping the membranes of cellular organelles. Annu Rev Cell Dev Biol 25:329-354. doi:10.1146/annurev.cellbio.042308.113324

87. Senda T, Yoshinaga-Hirabayashi T (1998) Intermembrane bridges within membrane organelles revealed by quick-freeze deep-etch electron microscopy. Anat Rec 251(3):339-345. doi:10.1002/(SICI)1097-0185(199807)251:3<339:AID-AR9>3. $0 . \mathrm{CO} ; 2-\mathrm{Q}$

88. Foster LJ, de Hoog CL, Zhang Y, Xie X, Mootha VK, Mann M (2006) A mammalian organelle map by protein correlation profiling. Cell 125(1):187-199. doi:10.1016/j.cell.2006.03.022

89. Nagaraj N, Wisniewski JR, Geiger T, Cox J, Kircher M, Kelso J, Paabo S, Mann M (2011) Deep proteome and transcriptome mapping of a human cancer cell line. Mol Syst Biol 7:548. doi:10.1038/msb.2011.81

90. Beck M, Schmidt A, Malmstroem J, Claassen M, Ori A, Szymborska A, Herzog F, Rinner O, Ellenberg J, Aebersold R (2011) The quantitative proteome of a human cell line. Mol Syst Biol 7:549. doi:10.1038/msb.2011.82

91. Klopfenstein DR, Kappeler F, Hauri HP (1998) A novel direct interaction of endoplasmic reticulum with microtubules. EMBO J 17(21):6168-6177. doi:10.1093/emboj/17.21.6168

92. Klopfenstein DR, Klumperman J, Lustig A, Kammerer RA, Oorschot V, Hauri HP (2001) Subdomain-specific localization of CLIMP-63 (p63) in the endoplasmic reticulum is mediated by its luminal alpha-helical segment. J Cell Biol 153(6):1287-1300

93. Nikonov AV, Hauri HP, Lauring B, Kreibich G (2007) Climp63-mediated binding of microtubules to the ER affects the lateral mobility of translocon complexes. J Cell Sci $120(\mathrm{Pt}$ 13):2248-2258. doi:10.1242/jcs.008979

94. Ogawa-Goto K, Tanaka K, Ueno T, Kurata T, Sata T, Irie S (2007) p180 is involved in the interaction between the endoplasmic reticulum and microtubules through a novel microtubule-binding and bundling domain. Mol Biol Cell 18(10):3741-3751. doi:10.1091/mbc.E06-12-1125

95. Toyoshima I, Yu H, Steuer ER, Sheetz MP (1992) Kinectin, a major kinesin-binding protein on ER. J Cell Biol 118(5):1121-1131 
96. Allan V, Vale R (1994) Movement of membrane tubules along microtubules in vitro: evidence for specialised sites of motor attachment. J Cell Sci 107(Pt 7):1885-1897

97. Allan VJ, Vale RD (1991) Cell cycle control of microtubulebased membrane transport and tubule formation in vitro. J Cell Biol 113(2):347-359

98. Lane JD, Allan VJ (1999) Microtubule-based endoplasmic reticulum motility in Xenopus laevis: activation of membraneassociated kinesin during development. Mol Biol Cell 10(6):1909-1922

99. Waterman-Storer CM, Gregory J, Parsons SF, Salmon ED (1995) Membrane/microtubule tip attachment complexes (TACs) allow the assembly dynamics of plus ends to push and pull membranes into tubulovesicular networks in interphase Xenopus egg extracts. J Cell Biol 130(5):1161-1169

100. Waterman-Storer CM, Salmon ED (1998) Endoplasmic reticulum membrane tubules are distributed by microtubules in living cells using three distinct mechanisms. Curr Biol 8(14):798-806 S0960-9822(98)70321-5 [pii]

101. Terasaki M, Chen LB, Fujiwara K (1986) Microtubules and the endoplasmic reticulum are highly interdependent structures. J Cell Biol 103(4):1557-1568

102. Desai A, Mitchison TJ (1997) Microtubule polymerization dynamics. Annu Rev Cell Dev Biol 13:83-117. doi:10.1146/ annurev.cellbio.13.1.83

103. Guttinger S, Laurell E, Kutay U (2009) Orchestrating nuclear envelope disassembly and reassembly during mitosis. Nat Rev Mol Cell Biol 10(3):178-191. doi:10.1038/nrm2641

104. Bobinnec Y, Marcaillou C, Morin X, Debec A (2003) Dynamics of the endoplasmic reticulum during early development of Drosophila melanogaster. Cell Motil Cytoskeleton 54(3):217-225. doi:10.1002/cm.10094

105. Poteryaev D, Squirrell JM, Campbell JM, White JG, Spang A (2005) Involvement of the actin cytoskeleton and homotypic membrane fusion in ER dynamics in Caenorhabditis elegans. Mol Biol Cell 16(5):2139-2153. doi:10.1091/mbc.E04-08-0726

106. McCullough S, Lucocq J (2005) Endoplasmic reticulum positioning and partitioning in mitotic $\mathrm{HeLa}$ cells. J Anat 206(5):415-425. doi:10.1111/j.1469-7580.2005.00407.x

107. Puhka M, Joensuu M, Vihinen H, Belevich I, Jokitalo E (2012) Progressive sheet-to-tubule transformation is a general mechanism for endoplasmic reticulum partitioning in dividing mammalian cells. Mol Biol Cell 23(13):2424-2432. doi:10. 1091/mbc.E10-12-0950

108. Anderson DJ, Hetzer MW (2007) Nuclear envelope formation by chromatin-mediated reorganization of the endoplasmic reticulum. Nat Cell Biol 9(10):1160-1166. doi:10.1038/ncb1636

109. Lu L, Ladinsky MS, Kirchhausen T (2011) Formation of the postmitotic nuclear envelope from extended ER cisternae precedes nuclear pore assembly. J Cell Biol 194(3):425-440. doi: $10.1083 /$ jcb. 201012063

110. Lu L, Ladinsky MS, Kirchhausen T (2009) Cisternal organization of the endoplasmic reticulum during mitosis. Mol Biol Cell 20(15):3471-3480. doi:10.1091/mbc.E09-04-0327

111. Olmos Y, Hodgson L, Mantell J, Verkade P, Carlton JG (2015) ESCRT-III controls nuclear envelope reformation. Nature 522(7555):236-239. doi:10.1038/nature 14503

112. Vietri M, Schink KO, Campsteijn C, Wegner CS, Schultz SW, Christ L, Thoresen SB, Brech A, Raiborg C, Stenmark H (2015) Spastin and ESCRT-III coordinate mitotic spindle disassembly and nuclear envelope sealing. Nature 522(7555):231-235. doi:10.1038/nature 14408

113. Hurley JH (2015) ESCRTs are everywhere. EMBO J. doi:10. 15252/embj.201592484

114. Bian Y, Song C, Cheng K, Dong M, Wang F, Huang J, Sun D, Wang L, Ye M, Zou H (2014) An enzyme assisted RP-RPLC approach for in-depth analysis of human liver phosphoproteome. J Proteomics 96:253-262. doi:10.1016/j.jprot.2013.11.014

115. Olsen JV, Blagoev B, Gnad F, Macek B, Kumar C, Mortensen P, Mann M (2006) Global, in vivo, and site-specific phosphorylation dynamics in signaling networks. Cell 127(3):635-648. doi:10.1016/j.cell.2006.09.026

116. Olsen JV, Vermeulen M, Santamaria A, Kumar C, Miller ML, Jensen LJ, Gnad F, Cox J, Jensen TS, Nigg EA, Brunak S, Mann M (2010) Quantitative phosphoproteomics reveals widespread full phosphorylation site occupancy during mitosis. Sci Signal 3(104):ra3. doi:10.1126/scisignal.2000475

117. Rigbolt KT, Prokhorova TA, Akimov V, Henningsen J, Johansen PT, Kratchmarova I, Kassem M, Mann M, Olsen JV, Blagoev B (2011) System-wide temporal characterization of the proteome and phosphoproteome of human embryonic stem cell differentiation. Sci Signal 4(164):rs3. doi:10.1126/scisignal. 2001570

118. Dephoure N, Zhou C, Villen J, Beausoleil SA, Bakalarski CE, Elledge SJ, Gygi SP (2008) A quantitative atlas of mitotic phosphorylation. Proc Natl Acad Sci USA 105(31):10762-10767. doi:10.1073/pnas.0805139105

119. Daub H, Olsen JV, Bairlein M, Gnad F, Oppermann FS, Korner R, Greff Z, Keri G, Stemmann O, Mann M (2008) Kinaseselective enrichment enables quantitative phosphoproteomics of the kinome across the cell cycle. Mol Cell 31(3):438-448. doi:10.1016/j.molcel.2008.07.007

120. Mayya V, Lundgren DH, Hwang SI, Rezaul K, Wu L, Eng JK, Rodionov V, Han DK (2009) Quantitative phosphoproteomic analysis of $\mathrm{T}$ cell receptor signaling reveals system-wide modulation of protein-protein interactions. Sci Signal 2(84):ra46. doi:10.1126/scisignal.2000007

121. Vedrenne C, Klopfenstein DR, Hauri HP (2005) Phosphorylation controls CLIMP-63-mediated anchoring of the endoplasmic reticulum to microtubules. Mol Biol Cell 16(4):1928-1937. doi:10.1091/mbc.E04-07-0554

122. Grigoriev I, Gouveia SM, van der Vaart B, Demmers J, Smyth JT, Honnappa S, Splinter D, Steinmetz MO, Putney JW Jr, Hoogenraad CC, Akhmanova A (2008) STIM1 is a MT-plusend-tracking protein involved in remodeling of the ER. Curr Biol 18(3):177-182. doi:10.1016/j.cub.2007.12.050

123. Smyth JT, Beg AM, Wu S, Putney JW Jr, Rusan NM (2012) Phosphoregulation of STIM1 leads to exclusion of the endoplasmic reticulum from the mitotic spindle. Curr Biol 22(16):1487-1493. doi:10.1016/j.cub.2012.05.057

124. Schlaitz AL, Thompson J, Wong CC, Yates JR 3rd, Heald R (2013) REEP3/4 ensure endoplasmic reticulum clearance from metaphase chromatin and proper nuclear envelope architecture. Dev Cell 26(3):315-323. doi:10.1016/j.devcel.2013.06.016

125. Vacquier VD (1981) Dynamic changes of the egg cortex. Dev Biol 84(1):1-26 (0012-1606(81)90366-3 [pii])

126. Whitaker M (2006) Calcium at fertilization and in early development. Physiol Rev 86(1):25-88. doi:10.1152/physrev.00023. 2005

127. Horner VL, Wolfner MF (2008) Transitioning from egg to embryo: triggers and mechanisms of egg activation. Dev Dyn 237(3):527-544. doi:10.1002/dvdy.21454

128. Perry AC, Verlhac MH (2008) Second meiotic arrest and exit in frogs and mice. EMBO Rep 9(3):246-251. doi:10.1038/embor. 2008.22

129. Stricker SA (2006) Structural reorganizations of the endoplasmic reticulum during egg maturation and fertilization. Semin Cell Dev Biol 17(2):303-313. doi:10.1016/j.semcdb.2006.02. 002

130. Terasaki M, Runft LL, Hand AR (2001) Changes in organization of the endoplasmic reticulum during Xenopus oocyte maturation and activation. Mol Biol Cell 12(4):1103-1116 
131. Kume S, Yamamoto A, Inoue T, Muto A, Okano H, Mikoshiba K (1997) Developmental expression of the inositol 1,4,5trisphosphate receptor and structural changes in the endoplasmic reticulum during oogenesis and meiotic maturation of Xenopus laevis. Dev Biol 182(2):228-239. doi:10.1006/dbio.1996.8479

132. Henson JH, Beaulieu SM, Kaminer B, Begg DA (1990) Differentiation of a calsequestrin-containing endoplasmic reticulum during sea urchin oogenesis. Dev Biol 142(2):255-269

133. Jaffe LA, Terasaki M (1994) Structural changes in the endoplasmic reticulum of starfish oocytes during meiotic maturation and fertilization. Dev Biol 164(2):579-587. doi:10.1006/dbio. 1994.1225

134. Mehlmann LM, Terasaki M, Jaffe LA, Kline D (1995) Reorganization of the endoplasmic reticulum during meiotic maturation of the mouse oocyte. Dev Biol 170(2):607-615. doi:10.1006/dbio.1995.1240

135. FitzHarris G, Marangos P, Carroll J (2007) Changes in endoplasmic reticulum structure during mouse oocyte maturation are controlled by the cytoskeleton and cytoplasmic dynein. Dev Biol 305(1):133-144. doi:10.1016/j.ydbio.2007.02.006

136. Mendez R, Richter JD (2001) Translational control by CPEB: a means to the end. Nat Rev Mol Cell Biol 2(7):521-529. doi:10. $1038 / 35080081$

137. Kessel RG (1992) Annulate lamellae: a last frontier in cellular organelles. Int Rev Cytol 133:43-120

138. Nuccitelli R, Yim DL, Smart T (1993) The sperm-induced $\mathrm{Ca}^{2+}$ wave following fertilization of the Xenopus egg requires the production of Ins(1, 4, 5)P3. Dev Biol 158(1):200-212. doi:10. 1006/dbio.1993.1179

139. Han JK, Nuccitelli R (1990) Inositol 1,4,5-trisphosphate-induced calcium release in the organelle layers of the stratified, intact egg of Xenopus laevis. J Cell Biol 110(4):1103-1110

140. Steinhardt R, Zucker R, Schatten G (1977) Intracellular calcium release at fertilization in the sea urchin egg. Dev Biol 58(1):185-196 0012-1606(77)90084-7 [pii]

141. Ridgway EB, Gilkey JC, Jaffe LF (1977) Free calcium increases explosively in activating medaka eggs. Proc Natl Acad Sci USA 74(2):623-627

142. Miyazaki S, Yuzaki M, Nakada K, Shirakawa H, Nakanishi S, Nakade S, Mikoshiba K (1992) Block of $\mathrm{Ca}^{2+}$ wave and $\mathrm{Ca}^{2+}$ oscillation by antibody to the inositol 1,4,5-trisphosphate receptor in fertilized hamster eggs. Science 257(5067):251-255

143. Terasaki M, Sardet C (1991) Demonstration of calcium uptake and release by sea urchin egg cortical endoplasmic reticulum. J Cell Biol 115(4):1031-1037

144. Terasaki M, Jaffe LA, Hunnicutt GR, Hammer JA 3rd (1996) Structural change of the endoplasmic reticulum during fertilization: evidence for loss of membrane continuity using the green fluorescent protein. Dev Biol 179(2):320-328 S0012160696902638 [pii]

145. Kline D, Mehlmann L, Fox C, Terasaki M (1999) The cortical endoplasmic reticulum (ER) of the mouse egg: localization of ER clusters in relation to the generation of repetitive calcium waves. Dev Biol 215(2):431-442. doi:10.1006/dbio.1999.9445

146. Mehlmann LM, Mikoshiba K, Kline D (1996) Redistribution and increase in cortical inositol 1,4,5-trisphosphate receptors after meiotic maturation of the mouse oocyte. Dev Biol 180(2):489-498. doi:10.1006/dbio.1996.0322

147. Tabas I, Ron D (2011) Integrating the mechanisms of apoptosis induced by endoplasmic reticulum stress. Nat Cell Biol 13(3):184-190. doi:10.1038/ncb0311-184

148. Nilsson IM, von Heijne G (1993) Determination of the distance between the oligosaccharyltransferase active site and the endoplasmic reticulum membrane. J Biol Chem 268(8):5798-5801
149. Jitsuhara Y, Toyoda T, Itai T, Yamaguchi H (2002) Chaperonelike functions of high-mannose type and complex-type $\mathrm{N}$-glycans and their molecular basis. J Biochem 132(5):803-811

150. Hanson SR, Culyba EK, Hsu TL, Wong CH, Kelly JW, Powers ET (2009) The core trisaccharide of an $N$-linked glycoprotein intrinsically accelerates folding and enhances stability. Proc Natl Acad Sci USA 106(9):3131-3136. doi:10.1073/pnas. 0810318105

151. Kaufman RJ (1999) Stress signaling from the lumen of the endoplasmic reticulum: coordination of gene transcriptional and translational controls. Genes Dev 13(10):1211-1233

152. Kaufman RJ, Scheuner D, Schroder M, Shen X, Lee K, Liu CY, Arnold SM (2002) The unfolded protein response in nutrient sensing and differentiation. Nat Rev Mol Cell Biol 3(6):411-421. doi: $10.1038 / \mathrm{nrm} 829$

153. Lee AS (1992) Mammalian stress response: induction of the glucose-regulated protein family. Curr Opin Cell Biol 4(2):267-273

154. Ron D, Walter P (2007) Signal integration in the endoplasmic reticulum unfolded protein response. Nat Rev Mol Cell Biol 8(7):519-529. doi:10.1038/nrm2199

155. Walter P, Ron D (2011) The unfolded protein response: from stress pathway to homeostatic regulation. Science 334(6059):1081-1086. doi:10.1126/science.1209038

156. Schuck S, Prinz WA, Thorn KS, Voss C, Walter P (2009) Membrane expansion alleviates endoplasmic reticulum stress independently of the unfolded protein response. J Cell Biol 187(4):525-536. doi:10.1083/jcb.200907074

157. Yanagitani K, Imagawa Y, Iwawaki T, Hosoda A, Saito M, Kimata Y, Kohno K (2009) Cotranslational targeting of XBP1 protein to the membrane promotes cytoplasmic splicing of its own mRNA. Mol Cell 34(2):191-200. doi:10.1016/j.molcel. 2009.02.033

158. Yoshida H, Matsui T, Yamamoto A, Okada T, Mori K (2001) XBP1 mRNA is induced by ATF6 and spliced by IRE1 in response to ER stress to produce a highly active transcription factor. Cell 107(7):881-891 S0092-8674(01)00611-0 [pii]

159. Lee K, Tirasophon W, Shen X, Michalak M, Prywes R, Okada T, Yoshida H, Mori K, Kaufman RJ (2002) IRE1-mediated unconventional mRNA splicing and S2P-mediated ATF6 cleavage merge to regulate XBP1 in signaling the unfolded protein response. Genes Dev 16(4):452-466. doi:10.1101/gad. 964702

160. Hollien J, Weissman JS (2006) Decay of endoplasmic reticulum-localized mRNAs during the unfolded protein response. Science 313(5783):104-107. doi:10.1126/science.1129631

161. Gaddam D, Stevens N, Hollien J (2013) Comparison of mRNA localization and regulation during endoplasmic reticulum stress in Drosophila cells. Mol Biol Cell 24(1):14-20. doi:10.1091/ mbc.E12-06-0491

162. Cao Y, Knochel S, Oswald F, Donow C, Zhao H, Knochel W (2006) XBP1 forms a regulatory loop with BMP-4 and suppresses mesodermal and neural differentiation in Xenopus embryos. Mech Dev 123(1):84-96. doi:10.1016/j.mod.2005.09. 003

163. Brar GA, Yassour M, Friedman N, Regev A, Ingolia NT, Weissman JS (2012) High-resolution view of the yeast meiotic program revealed by ribosome profiling. Science 335(6068):552-557. doi:10.1126/science.1215110

164. Davidowitz J, Philips GH, Pachter BR, Breinin GM (1975) Particle-free and glycogen-bearing double membrane arrays in extraocular muscle of rabbit. Am J Pathol 78(2):191-198 